\title{
PENDIDIKAN BAGI GENERASI MILENIAL DI SMA ALMANAR AZHARI ISLAMIC BOARDING SCHOOL DEPOK, JAWA BARAT
}

\author{
Diana Riyana H, Endang Susilo Wardani, Oki Iqbal Khair, Nelwati Tanius, \\ Reza Octovian \\ Universitas Pamulang \\ Email:dosen01788@unpam.ac.id
}

\begin{abstract}
At present, what is needed between students and educators is understanding each other. Understanding each other to prevent mis communication between students and educators so that it will result in social inequality, mistaken understanding of science and impact on poor practice in daily life. The purpose of this activity is to share knowledge from the Community Service Program Team (PKM), Pamulang University (UNPAM) to the Almanar Azhari Islamic Boarding School about how professional teachers in improving the quality of education for millennial generation in Islamic values. With better understanding the character of millennial generation so professional teacher can built strategy and creative learning with fun educational environment.
\end{abstract}

Keywords: Education, Millennial Generation, Teacher Professionals

\begin{abstract}
Abstrak
Saling memahami antara satu dengan yang lainnya untuk mencegah komunikasi yang salah di antara anak didik dan pendidik sehingga akan mengakibatkan kesenjangan sosial, kelirunya pemahaman pada ilmu dan berimbas pada buruknya pempraktekkan dalam kehidupan sehari-hari. Tujuan dari kegiatan Pengabdian Kepada Masyarakat ini adalah membagi ilmu dari Tim Program Pengabdian Kepada Masyarakat (PKM), Universitas Pamulang (UNPAM) kepada sekolah Almanar Azhari Islamic Boarding School tentang bagaimana profesional guru dalam meningkatkan kualitas mendidik dan pendidikan bagi generasi milenial dalam nilai-nilai Islam. Dengan pemahaman yang lebih baik tentang karakter generasi milenial sehingga profesional guru dapat merencanakan strategi pembelajaran yang kreatif dengan lingkungan pendidikan yang menyenangkan.
\end{abstract}

Kata Kunci: Pendidikan, Generasi Milenial, Profesional Guru 


\section{A. PENDAHULUAN}

Dalam kajian Islam model pembelajaran sudah diajarkan oleh Rasulullah SAW, mulai dari yang klasik hingga saat ini dikembangkan oleh para ilmuawan Barat. Bagaimanapun secara tidak langsung mereka terinspirasi dari agama Islam yang telah dicantumkan oleh Rasulullah SAW, seperti metode ceramah, metode dialog dan tanya jawab, metode qishah (cerita), metode tamtsil (pemisahan), metode targhib (motivasi), metode tarhin (menakut-nakuti), metode qasam (sumpah), metode keteladanan dan lain-lain.

Proses penyampaian materi yang dilakukan Rasulullah SAW, dapat menjadi menarik dengan menggunakan metode yang tepat sesuai kadar materi yang sedang dibahas. Namun Beliau juga tidak jarang dalam menggunakan metode bermain untuk menghilangkan suasana tegang. Sehingga setiap pelajaran yang diberikan oleh Rasulullah SAW, dapat diterima dengan baik serta menjadi amalan bagi peserta didiknya.

Saat ini,yang dibutuhkan oleh peserta didik dan pendidik harus melengkapi satu sama lain. Saling memahami antara satu dengan yang lainnya, agar tidak terjadi hilang komunikasi sebab komunikasi yang salah di antara anak didik dan pendidik akan mengakibatkan kesenjangan sosial, kelirunya pemahaman pada ilmu dan berimbas pada buruknya praktek dalam kehidupan sehari-hari.

Tujuan dari kegiatan Pengabdian Kepada Masyarakat ini adalah membagi ilmu dari Tim Program Pengabdian Kepada Masyarakat (PKM), Universitas Pamulang (UNPAM) kepada sekolah Almanar Azhari Islamic Boarding School tentang bagaimana profesional guru dalam meningkatkan kualitas mendidik dan pendidikan bagi generasi milenial dalam nilai-nilai Islam.

Kegiatan ini bermanfaat bagi Tim Program Pengabdian Kepada Masyarakat (PKM), Universitas Pamulang (UNPAM) yang dapat mengaplikasikan ilmunya kepada masyarakat pada umumnya dan khususnya untuk Almanar Azhari Islamic Boarding School sebagai sekolah sekaligus pesantren yang memberikan ilmu umum dan ilmu agama selama 24 jam sehingga membentuk karakter peserta didik bukan hanya ber ilmu tetapi juga ber-iman, ber takwa dan ber- akhlak mulia.

\section{B. METODE PELAKSANAAN KEGIATAN}

Dalam rangka menciptakan guru profesional yang berkinerja tinggi pada setiap lembaga pendidikan,Undang-Undang Republik Indonesia Nomor 14 Tahun 2005 Pasal 8 tentang menjadi pendidik profesional tersebut ditegaskan, "Guru wajib memiliki kualifikasi akademik, kompetensi, sertifikasi pendidik, sehat jasmani dan rohani, serta memiliki kemampuan untuk mewujudkan tujuan pendidikan nasional". Sementara disisi lain saat ini karakter peserta didik yang sejak kecil mereka sudah mengenal teknologi dan akrab dengan gadget canggih yang secara tidak langsung berpengaruh terhadap kepribadian mereka dan pola penyerapan materi menjadi tantangan tersendiri dalam menyampaikan ilmu pendidikan.

Dari permasalahan diatas kemudian direalisasikan dalam aktivitas penyampaian materi mengenai ciri-ciri generasi milenial dan tantangannya, sikap pendidik dalam menghadapi generasi milenial. Kemudian dilanjutkan dengan diskusi dan tanya jawab mengenai permasalahan dalam mendidik generasi milenial. 


\section{HASIL DAN PEMBAHASAN}

Dalam pelaksanaan kegiatan pengabdian kepada masyarakat di sekolah/pesantren Almanar Azhari Islamic Boarding School - Limo, Kota Depok, Jawa Barat terdapat beberapa rangkaian kegiatan sebagai berikut :

1. Persiapan acara

Panitia melakukan persiapan sejak pukul 14.00 untuk memastikan segala sarana yang dapat menunjang kegiatan telah disiapkan dengan baik. Permasalahan seputar sarana dan prasana dapat diminimalkan dengan saling berkerja sama antar panitia dalam mempersiapkan kegiatan. Sarana penunjang dalam penyampaian materi dipersiapkan oleh pihak panitia dari Unpam

2. Pembukaan acara dan pembacaan ayat suci Al Quran

Acara dibuka oleh MC dan dilanjutkan dengan pembacaan ayat suci Al Quran menambah khihmat acara

3. Sambutan Kepala Sekolah Almanar Azhari Islamic Boarding School

Dalam sambutan disampaikan agar para pelajar meyimak materi yang disampaikan sehingga diharapkan akan menjadi masukan yang baik dan termotivasi untuk berprestasi lebih baik.

4. Sambutan dari Ketua Pelaksana PKM

Kegiatan pelatihan yang dilakukan sebagai salah satu bentuk pengabdian masyarakat yang merupakan bagian dari pengamalan Tri Dharma Perguruan Tinggi.Selain itu diharapkan dapat memberikan motivasi bagi pendidik di lingkungan sekolah/pesantren Almanar Azhari Islamic Boarding School

5. Penyampaian Materi dan Ice Breaking

Tema yang disampaikan oleh 1 pembicara, yaitu : Profesional Guru dalam Kualitas Mendidik. Dengan mengetahui permasalahan yang disampaikan maka pembicara memberikan masukan dan tips bagi para pendidik di lingkungan sekolah/pesantren Almanar Azhari Islamic Boarding School

6. Tema yang disampaikan oleh 2 pembicara, yaitu : Pendidikan bagi Generasi Milenial di era kemajuan teknologi menjadi tantangan tersendiri dalam melakukan tugasnya mendidik generasi muda. Setelah penyampaian materi, dilanjutkan tanya jawab dan diskusi terkait tips dalam menciptakan lingkungan pendidikan yang kondusif dan menantang agar generasi milenial lebih bersemangat tidak hanya dalam mempelajari tapi juga mengaplikasikan ilmunya karena kedepannya akan berperan sebagai change agent.

7. Penyerahan sourvernir / cinderamata

Penyerahan Cinderamata telah dipersiapkan oleh pihak Universitas Pamulang kepada pihak sekolah/pesantren Almanar Azhari Islamic Boarding School - Limo, Kota Depok, Jawa Barat sebagai bentuk ucapan terima kasih atas kerjasama dalam penyelanggaraan kegiatan ini.

8. Penutupan dan pembacaan doa penutup

Dilakukan penutupan acara dan doa bersama sebagai rasa syukur atas pelaksanaan acara yang berjalan lancar dan harapan semoga yang telah disampaikan pada acara tersebut dapat bermanfaat bagi peserta. 


\section{KESIMPULAN DAN SARAN}

\section{Kesimpulan}

Berdasarkan pelaksanaan kegiatan pengabdian kepada masyarakat yang dilaksanakan di sekolah/pesantren Almanar Azhari Islamic Boarding School - Limo, Kota Depok, Jawa Barat pada tanggal 20 - 22 Februari 2020 dapat diambil kesimpulan bahwa secara umum kegiatan pengabdian kepada masyarakat dapat terlaksana dengan baik dan mendapat dukungan dari pihak sekolah. Dengan tantangan di era digital yang sangat berpengaruh dalam pola pendidikan saat ini sehingga sebagai pendidik akan dituntut untuk lebih kreatif dan inovatif dalam penciptaan pembelajaran yg menantang tetapi asyik untuk diikuti (menyenangkan). Kami berharap materi yang disampaikan dapat bermanfaat untuk memotivasi para pendidik dalam meningkatkan kualitas mendidik dan pendidikan bagi generasi milenial dalam nilai-nilai Islam.

\section{Saran}

Berdasarkan kegiatan yang sudah terlaksana, saran yang dapat disampaikan adalah bagaimana para pendidik dapat lebih memahami karakter dari generasi milenial dan mengupayakan strategi dalam proses belajar dan mengajar yang profesional dan kreatif.

\section{Ucapan Terima Kasih}

Rasa syukur dan suka cita kamu haturkan kepada segenap pihak yang telah mensukseskan kegiatan PKM dengan judul "Pendidikan Bagi Generasi Mileneal Di SMA Almanar Azhari Islamic Boarding School Depok, Jawa Barat ” kepada:

1. Rektor Dr. H. Dayat Hidayat, M.M, Rektor Universitas Pamulang Tangerang Selatan Banten.

2. Dr. Ali Maddinsyah, S.E., M.M., selaku Ketua LPPM Universitas Pamulang Tangerang Selatan - Banten.

3. Dr. Kasmad, S.E., M.,M., selaku Ketua Program Studi Manajemen Universitas Pamulang Tangerang Selatan - Banten.

4. Dr. Udin Ahidin, S.E., M.M., C.M.A, Selaku Wakil Program Studi Manajemen Universitas Pamulang Tangerang Selatan - Banten.

5. Drs. Waluyo Jati, M.M., Selaku Sekretaris Program Studi Manajemen Universitas Pamulang Tangerang Selatan - Banten.

6. Bapak Sony hidayat, S.Pd., selaku Kepala SMA Almanar Azhari Boarding School Depok, Jawa Barat.

7. Mahasiswa Universitas Pamulang yang juga ikut berkontribusi terhadap kelancaran kegiatan PKM. 


\section{DAFTAR PUSTAKA}

Among Makarti, (2014). Pendidikan karakter berbasis tradisi pesantren. Jakarta: Rumah Kitab.

Putra, Yanuar Surya. (2016) Theoritical Review: Teori Perbedaan Generasi. Vol. 9 No. 18.

Arikunto, Suharsimi dan Lia Yuliana, (2008) Manajemen Pendidikan, cet. ke-1, Yogyakarta: Aditya Media bekerjasama dengan Fakultas Ilmu Pendidikan Universitas Negeri Yogyakarta.

Lalo, Kalfaris. (2018). Menciptakan Generasi Milenial Berkarakter dengan Pendidikan Karakter guna Menyongsong Era Globalisasi.Jurnal Ilmu Kepolisian Volume 12 Nomor 2.

Mastuhu. (1999). Memberdayakan Sistem Pendidikan Islam, Jakarta: Logos.

Mike Frye, at all. (2002). Character Education Informational Handbook and Guide. Public Schools of North Carolina State Board of Education Department of Public Instruction Division of Instructional Services Character Education.

Nurina, Siti Hakim dan Aliffatullah Alyu Raj.Dampak kecanduan internet (internet addiction) pada remaja.Prosiding Temu Ilmiah X Ikatan Psikologi Perkembangan Indonesia.

Rafid, R. (2018). Konsep Kepribadian Muslim Muhammad Iqbal Perspektif Pendidikan Islam sebagai Upaya Pengembangan dan Penguatan Karakter Generasi Milenial. JMP Online, 2(7), 711-718.

Sawaluddin. Eksistensi PKN sebagai Pendidikan Nilai dalam Membangun Karakter Bangsa. Tingkap, VIII (2), 145-158.

Sawaluddin. (2018). Konsep Evaluasi dalam Pembelajaran Pendidikan Islam. Jurnal AlThariqah, 3(1), 39-53. 2018

Wahono, M. (2018). Pendidikan Karakter: Suatu Kebutuhan Bagi Mahasiswa di Era Milenial. Integralistik, XXIX (2), 1-8. 